\title{
An application of DEA method for ranking different Tehran municipality branches
}

\author{
Seyed Hossein Miri ${ }^{\mathrm{a}}$, Younos Vakil Alroaia ${ }^{\mathrm{a}}$ and Simin Bohlouli ${ }^{\mathrm{b}^{*}}$
}

\begin{abstract}
${ }^{a}$ Assistant Professor and Chairman, Department of Management, Semnan Branch, Islamic Azad University, Semnan, Iran, P.O.Box 35145-175 ${ }^{b}$ Masters in Financial Management, Department of Management, Semnan Branch, Islamic Azad University, Semnan, Iran, P.O.Box 35145-175

CHR O N I C L E

Article history:

Received 5 January 2014

Received in revised format 8 March 2014

Accepted 16 March 2014

Available online

18 March 2014

Keywords:

Data envelopment analysis A B S T R A C T

Measuring the performance of governmental organizations plays essential role on making strategic decisions. In this paper, we present an empirical investigation to measure the performance of 22 different branches of municipalities in city of Tehran, Iran. The proposed study uses data envelopment analysis (DEA) for measuring the relative efficiencies of various units. The proposed DEA uses fixed assets, employee expenses and total income as input and Green Space Development, Resumption and Waste, Development of Cultural Spaces as well as Improvement of Passages and highways are considered as the output of the model. The results indicate that 9 regions were operating efficiently and 14 regions were inefficient.
\end{abstract}

Municipality

Performance measurement
(C) 2014 Growing Science Ltd. All rights reserved.

\section{Introduction}

For years, there have been outstanding attempts on applying various techniques for computing the relative efficiency of similar business units (Kuah et al., 2010; Cooper et al., 2011). Data envelopment analysis (DEA) is one of the most popular methods for measuring non-financial units (Charnes, 1978) and it has been successfully applied for measuring the performance of various technologies (Khouja, 1995), in airport industry (Roghanian \& Foroughi, 2010), supplier selection (Levary, 2008; Azar et al., 2011; Nourbakhsh et al., 2013) and heath care (Ghotbuee et al., 2012; Khani et al., 2012). Charnes et al. $(1978,1985,1990)$ are named as the first who introduced the idea of comparing non-financial units based on different inputs/outputs. There are various kinds of DEA methods including constant return to scale, variable return to scale, input/output oriented, etc.

DEA has been extensively implemented in rural industry for several years (Minciardi et al., 2008). Rogge and De Jaeger (2012) proposed an adjusted "shared-input" model of DEA, which helps evaluating municipality waste collection and processing performances in settings in which one waste costs are shared among treatment efforts of multiple municipal solid waste fractions. The proposed

*Corresponding author.

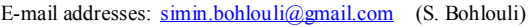


DEA not only provides an estimate of the municipalities overall cost efficiency but also provides forecasts on the municipalities' cost efficiency in the treatment of the various fractions of municipal solid waste.

lo Storto, C. (2013) presented findings of an exploratory study aimed at evaluating expenditure efficiency of 103 Italian major municipalities. The study applied DEA to calculate an efficiency score and investigated economies of scale. Their findings disclosed that there were some scale inefficiencies in a number of municipalities that need an in depth investigation. Rogge and De Jaeger (2013) proposed an adjusted version of the popular efficiency measurement DEA, which makes it possible to evaluate the cost efficiency of municipalities in the collection and processing of multiple household waste fractions. The method is also capable of robustifying the cost efficiency evaluations for the effect of measurement errors in the data or municipalities with outlying and atypical performances. The method also corrected the evaluations for differences in the operating environments of municipalities such as demography and median income of the municipality population.

\section{The proposed study}

In this paper, we present an empirical investigation to measure the relative efficiency of various units using data envelopment analysis (DEA).

\subsection{DEA model}

\subsection{The DEA method}

There are literally various DEA methods and the constant return to scale DEA (CCR) introduced by Charnes, et al. $(1978,1985,1994)$ is explained in this paper for measuring the relative efficiency of various decision making units (DMU). In this method we form a set of production feasibility, which constituts of various principles such as fixed-scale efficiency, convexity and feasibility as follows,

$$
T_{C}=\left\{(X, Y) \mid X \geq \sum_{j=1}^{n} \lambda_{j} X_{j}, Y \leq \sum_{j=1}^{n} \lambda_{j} Y_{j}, \lambda_{j} \geq 0, j=1, \cdots n\right\},
$$

where $X$ and $Y$ state the input and output vectors, respectively. The CCR production feasibility set border provides the relative efficiency where any off-border DMU is stated as inefficient. The CCR model can be measured in two types of either input or output oriented. The input CCR tries to decrease the maximum input level with a ratio of $\theta$ so that, at least, the same output is produced, i.e.:

$\min \theta$

subject to

$$
\begin{aligned}
& \theta X_{p}-\sum_{j=1}^{n} \lambda_{j} X_{i j} \geq 0, \\
& \sum_{j=1}^{n} \lambda_{j} Y_{r j} \geq Y_{r p}, \\
& \lambda_{j} \geq 0, \quad j=1, \cdots, n .
\end{aligned}
$$

Model (2) is an envelopment form of input CCR where $\theta$ is the relative efficiency of the DMU and it is possible to demonstrate that the optimal value of $\theta, \theta^{*}$, is located between zero and one. In an input oriented DEA model, once the efficiency of a DMU unit, $D M U_{p}$, lies in case of inefficiency, one may directs it towards the border to change it efficient. 


\subsubsection{Input/output}

The proposed study of this paper uses three inputs and four outputs for measuring the relative efficiencies of various units. Fig. 1 shows details of the propsoed study.

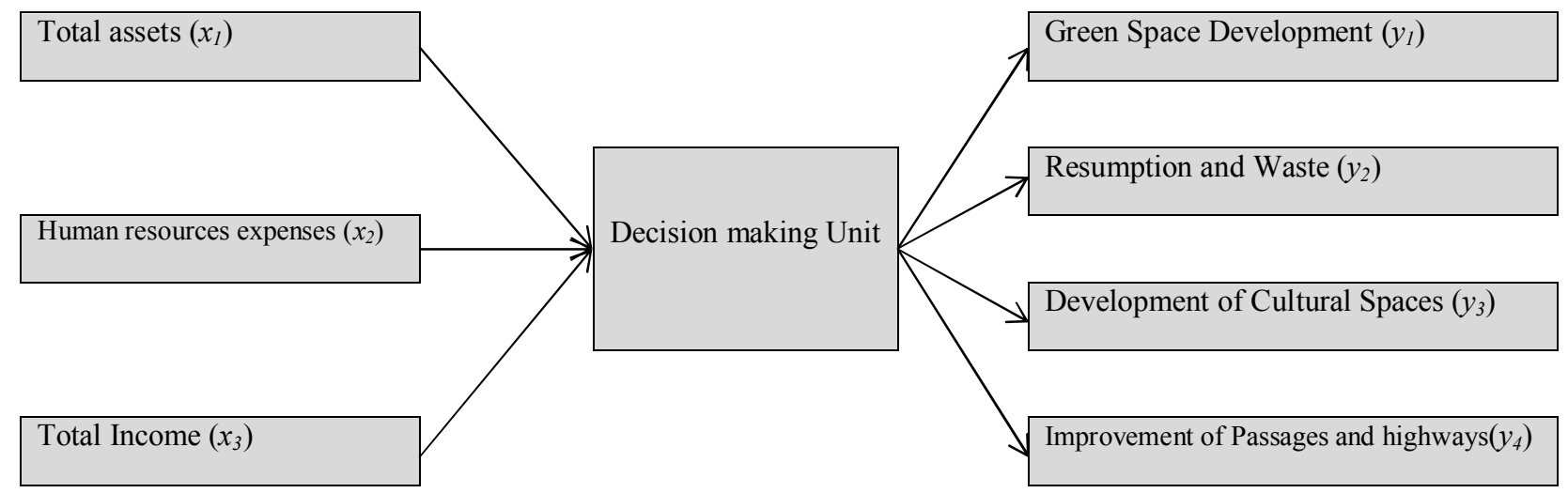

Fig. 1. The structure of the proposed study

Next, we present details of the DEA implementation based on model (2).

\section{The results}

We first present the optimal weights of input/output parameters computed by input oriented DEA method. Table 1 shows details of our results.

Table 1

The optimal weights of input/output

\begin{tabular}{ccccccc}
\hline \multicolumn{3}{c}{ Input } & \multicolumn{5}{c}{ Output } \\
\hline $\mathrm{x}_{1}$ & $\mathrm{x}_{2}$ & $\mathrm{x}_{3}$ & $\mathrm{y}_{1}$ & $\mathrm{y}_{2}$ & $\mathrm{y}_{3}$ & $\mathrm{y}_{4}$ \\
\hline 0.8375001 & 0.623456 & 0.7862921 & 0.934251 & 0.5656783 & 0.683901 & 0.7745301 \\
\hline
\end{tabular}

In addition, Table 2 demonstrates the summary of relative efficiencies of 22 units along with the values of dual variables associated with input/output.

Table 2

The results of DEA implementation

\begin{tabular}{|c|c|c|c|c|c|c|c|c|c|}
\hline \multicolumn{3}{|c|}{ Score } & \multicolumn{3}{|c|}{ Inputs } & \multicolumn{4}{|c|}{ Output } \\
\hline & & $\mathrm{Z}$ & V(i1) & $\mathrm{V}(\mathrm{i} 2)$ & V(i3) & V(i1) & $\mathrm{V}(\mathrm{i} 2)$ & $\mathrm{V}(\mathrm{i} 3)$ & V(i4) \\
\hline DMU & 1 & 1.00 & 0.000 & 0.000 & 0.089 & 0.000 & 0.000 & 0.000 & 0.021 \\
\hline DMU & 2 & 1.00 & $\mathbf{0 . 0 0 0}$ & 0.078 & $\mathbf{0 . 0 0 0}$ & 0.000 & 7.923 & 0.008 & 0.000 \\
\hline DMU & 3 & 0.84 & 0.000 & 0.000 & 0.091 & 0.000 & 0.000 & 0.021 & 0.011 \\
\hline DMU & 4 & 1.00 & $\mathbf{0 . 0 0 0}$ & 0.081 & $\mathbf{0 . 0 0 0}$ & 3.135 & 0.000 & 0.031 & 0.000 \\
\hline DMU & 5 & 1.00 & $\mathbf{0 . 0 0 0}$ & 0.078 & $\mathbf{0 . 0 0 0}$ & 0.000 & 1.262 & 0.000 & $\mathbf{0 . 0 2 0}$ \\
\hline DMU & 6 & 0.93 & 0.018 & 0.000 & 0.070 & 0.000 & 0.000 & 0.020 & 0.012 \\
\hline DMU & 7 & 0.93 & 0.000 & 0.000 & 0.091 & 0.000 & 0.000 & 0.025 & 0.009 \\
\hline DMU & 8 & 0.89 & 0.000 & 0.082 & 0.000 & 0.000 & 0.000 & 0.013 & 0.016 \\
\hline DMU & 9 & 0.92 & 0.000 & 0.084 & 0.000 & 0.000 & 0.000 & 0.038 & 0.000 \\
\hline DMU & 10 & 0.81 & 0.000 & 0.000 & 0.000 & 0.000 & 0.000 & 0.038 & 0.000 \\
\hline DMU & 11 & 0.97 & 0.039 & 0.044 & 0.000 & 0.000 & 0.000 & 0.015 & 0.016 \\
\hline DMU & 12 & 0.90 & 0.000 & 0.082 & 0.000 & 0.000 & 0.000 & 0.014 & 0.016 \\
\hline DMU & 13 & 1.00 & 0.084 & 0.000 & 0.000 & 4.651 & 0.000 & 0.026 & 0.000 \\
\hline DMU & 14 & 0.63 & 0.083 & 0.000 & 0.000 & 0.000 & 1.238 & 0.000 & 0.022 \\
\hline DMU & 15 & 1.00 & 0.084 & 0.000 & 0.000 & 0.000 & 0.000 & 0.037 & 0.000 \\
\hline DMU & 16 & 0.93 & 0.019 & 0.000 & 0.071 & 0.000 & 0.000 & 0.020 & 0.012 \\
\hline DMU & 17 & 0.89 & 0.040 & 0.045 & 0.000 & 0.000 & 0.000 & 0.015 & 0.016 \\
\hline DMU & 18 & 0.94 & 0.083 & 0.000 & 0.000 & 0.000 & 0.000 & 0.011 & 0.018 \\
\hline DMU & 19 & 1.00 & 0.085 & 0.000 & 0.000 & 1.554 & 0.000 & 0.016 & 0.014 \\
\hline DMU & 20 & 0.97 & 0.083 & 0.000 & 0.000 & 0.000 & 0.230 & 0.010 & 0.017 \\
\hline DMU & 21 & 1.00 & 0.061 & 0.022 & 0.000 & 4.515 & 0.000 & 0.026 & 0.000 \\
\hline DMU & 22 & 1.00 & 0.079 & 0.000 & 0.000 & 7.042 & 0.000 & 0.000 & 0.000 \\
\hline
\end{tabular}


According to the results of Table 1,9 units are detected as efficient units and 14 units are found inefficient. The average efficiency of these 14 inefficient units is equal to 0.93 , which means they have to reduce approximately $7 \%$ of their inputs. Based on the optimal weights computed for inefficient units, we may find efficient amount of inputs for the 14 inefficient units. For instance for unit 3, we have

$$
\begin{aligned}
& x_{1} \leftarrow \theta^{*} \mathrm{x} 1-s^{-*}=0.84 \times 12.939-0.07=10.8, \\
& x_{2} \leftarrow \theta^{*} \mathrm{x} 2-s^{-*}=0.84 \times 12.460-0.04=10.42, \\
& x_{3} \leftarrow \theta^{*} \mathrm{x} 3-s^{-*}=0.84 \times 11.035-0=9.3 .
\end{aligned}
$$

As we can observe, unit 3 has to reduce its fixed assets, employee expenses and total income from $12.939,12.460$ and 11.035 to $10.8,10.42$ and 9.3, respectively. Similarly, we can compute the efficient numbers for other units and Table 2 summarizes the results of our survey.

\begin{tabular}{|c|c|c|c|c|c|c|c|c|c|c|}
\hline & \multicolumn{3}{|c|}{ EFFICENCY } & \multicolumn{2}{|c|}{ Input-excess } & \multirow[b]{2}{*}{$\mathrm{t}(\mathrm{o} 1)$} & \multirow[b]{2}{*}{$\mathrm{t}(02)$} & \multirow[b]{2}{*}{$\mathrm{T}(03)$} & \multirow[b]{2}{*}{$\mathrm{T}(04)$} & \multirow[t]{2}{*}{ Output-shortfall } \\
\hline & & $\mathrm{z}$ & s(i1) & $\mathrm{s}(\mathrm{i} 2)$ & $\mathrm{s}(\mathrm{i} 3)$ & & & & & \\
\hline$\overline{\mathrm{DMU}}$ & 1 & 1.00 & 0.00 & 0.00 & 0.00 & 0.00 & 0.00 & 0.00 & 0.00 & Lambda(dmu1) $=1.00$ \\
\hline $\mathrm{DMU}$ & 3 & 0.84 & 0.07 & 0.04 & 0.00 & 0.01 & 0.01 & 0.00 & 0.00 & $\operatorname{Lambda}(\mathrm{dmu} 1)=0.25 \operatorname{lambada}(\mathrm{dmu} 4)=0.58$ \\
\hline DMU & 6 & 0.93 & 0.00 & 0.11 & 0.00 & 0.02 & 0.03 & 0.00 & 0.00 & $\operatorname{Lambda}(\mathrm{dmu} 1)=0.30 \mathrm{lambda}(\mathrm{dmu} 4)=0.55 \mathrm{lambda}$ \\
\hline DMU & 7 & 0.93 & 0.41 & 0.02 & 0.00 & 0.04 & 0.03 & 0.00 & 0.00 & $\operatorname{Lambda}(\mathrm{dmu} 4)=0.36$ lambda $(\mathrm{dmu} 15)=0.56$ \\
\hline DMU & 8 & 0.89 & 0.02 & 0.00 & 0.08 & 0.04 & 0.03 & 0.00 & 0.00 & $\operatorname{Lambda}($ dmu1 $)=0.28$ lambda $($ dmu 4$)=0.59$ \\
\hline DMU & 9 & 0.92 & 0.24 & 0.00 & 0.17 & 0.02 & 0.03 & 0.00 & 0.83 & Lambda $($ dmu15 $)=0.88$ \\
\hline DMU & 10 & 0.81 & 0.18 & 0.12 & 0.00 & 0.03 & 0.01 & 0.00 & 1.71 & $\operatorname{Lambda}(\mathrm{dmu} 15)=0.79$ \\
\hline DMU & 11 & 0.97 & 0.00 & 0.00 & 0.58 & 0.03 & 0.01 & 0.00 & 0.00 & $\operatorname{Lambda}(\mathrm{dmu} 1)=0.65 \mathrm{lambda}(\mathrm{dmu} 4)=0.21$ lambda \\
\hline DMU & 12 & 0.90 & 0.01 & 0.00 & 0.52 & 0.02 & 0.00 & 0.00 & 0.00 & $\operatorname{Lambda}($ dmu1 $)=0.71$ lambda $($ dmu 4$)=0.13$ \\
\hline DMU & 14 & 0.63 & 0.00 & 0.20 & 0.51 & 0.01 & 0.00 & 1.17 & 0.00 & $\operatorname{Lambda}($ dmu1 $)=0.34$ lambda $($ dmu5 $)=0.22$ \\
\hline DMU & 16 & 0.93 & 0.00 & 0.35 & 0.00 & 0.01 & 0.02 & 0.00 & 0.00 & $\operatorname{Lambda}(\operatorname{dmu} 1)=0.21$ lambda $(\mathrm{dmu} 4)=0.03$ lambda \\
\hline DMU & 17 & 0.89 & 0.00 & 0.00 & 0.60 & 0.04 & 0.02 & 0.00 & 0.00 & $\operatorname{Lambda}(\mathrm{dmu} 1)=0.32$ lambda $(\mathrm{dmu} 4)=0.41$ lambda \\
\hline DMU & 18 & 0.94 & 0.00 & 0.21 & 0.58 & 0.00 & 0.01 & 0.00 & 0.00 & $\operatorname{Lambda}($ dmu1 $)=0.56$ lambda $($ dmu15 $)=0.33$ \\
\hline DMU & 20 & 0.97 & 0.00 & 0.10 & 0.21 & 0.00 & 0.00 & 0.00 & 0.00 & $\operatorname{Lambda}(\mathrm{dmu} 1)=0.25 \mathrm{lambda}(\mathrm{dmu} 4)=0.041 \mathrm{ambda}$ \\
\hline
\end{tabular}

Table 2

The summary of efficient resources

Next, we present details of our findings on present and optimal values of inefficient units in Table 3 as follows,

\begin{tabular}{|c|c|c|c|c|c|c|}
\hline & \multicolumn{3}{|c|}{ Initial } & \multicolumn{3}{|c|}{ Final } \\
\hline & $x_{1}$ & $\mathrm{x}_{2}$ & $\mathrm{x}_{3}$ & $x_{1}$ & $\mathrm{x}_{2}$ & $\mathrm{x}_{3}$ \\
\hline DMU1 & 13.45 & 13.10 & 11.27 & 13.45 & 13.10 & 11.27 \\
\hline DMU2 & 13.05 & 12.87 & 11.21 & 13.05 & 12.87 & 11.20 \\
\hline DMU3 & 12.94 & 12.46 & 11.04 & 10.84 & 10.47 & 9.30 \\
\hline DMU4 & 12.88 & 12.40 & 11.18 & 12.88 & 12.40 & 11.18 \\
\hline DMU5 & 13.01 & 12.77 & 11.13 & 13.01 & 12.77 & 11.13 \\
\hline DMU6 & 12.77 & 12.52 & 11.02 & 11.90 & 11.56 & 10.26 \\
\hline DMU7 & 12.57 & 12.21 & 11.02 & 11.24 & 11.30 & 10.22 \\
\hline DMU8 & 12.71 & 12.25 & 10.96 & 11.29 & 10.90 & 9.68 \\
\hline DMU9 & 11.72 & 11.88 & 10.94 & 10.52 & 10.89 & 9.86 \\
\hline DMU10 & 11.89 & 12.24 & 10.94 & 9.43 & 9.77 & 8.85 \\
\hline DMU11 & 12.22 & 11.90 & 10.97 & 11.91 & 11.60 & 10.10 \\
\hline DMU12 & 12.49 & 12.14 & 11.10 & 11.20 & 10.89 & 9.43 \\
\hline DMU13 & 11.92 & 11.99 & 11.04 & 11.93 & 11.99 & 11.04 \\
\hline DMU14 & 12.06 & 12.10 & 11.00 & 7.54 & 7.37 & 6.37 \\
\hline DMU15 & 11.90 & 12.32 & 11.16 & 11.90 & 12.32 & 11.16 \\
\hline DMU16 & 11.98 & 12.56 & 10.90 & 11.17 & 11.37 & 10.17 \\
\hline DMU17 & 11.95 & 11.65 & 10.98 & 10.69 & 10.42 & 9.22 \\
\hline DMU18 & 12.04 & 12.20 & 11.11 & 11.37 & 11.31 & 9.91 \\
\hline DMU19 & 11.72 & 12.29 & 10.90 & 11.68 & 11.88 & 10.75 \\
\hline DMU20 & 12.05 & 12.30 & 11.08 & 11.65 & 11.80 & 10.51 \\
\hline DMU21 & 12.12 & 11.91 & 10.89 & 12.12 & 11.91 & 10.89 \\
\hline DMU22 & 12.66 & 12.73 & 11.04 & 12.66 & 12.73 & 11.04 \\
\hline
\end{tabular}

Table 3

The summary of efficient weights of input projection points 
Finally, we use Anderson-Peterson method (Andersen \& Petersen, 1993) to provide performance measurement among 9 efficient units and Table 4 shows details of our findings.

Table 4

The summary of ranking efficient units based on Anderson-Peterson method

\begin{tabular}{lccccccccc}
\hline & \multicolumn{3}{c}{ EFFICENCY } & \multicolumn{4}{c}{ Input-excess } & \multicolumn{4}{c}{ Output-shortfall } \\
& Unit & $\mathrm{z}$ & $\mathrm{V} 1$ & $\mathrm{~V} 2$ & $\mathrm{~V} 3$ & $\mathrm{U} 1$ & $\mathrm{U} 2$ & $\mathrm{U} 3$ & $\mathrm{U} 4$ \\
\hline DMU & 1 & 1.10 & 0.000 & 0.000 & 0.089 & 0.000 & 0.000 & 0.005 & 0.020 \\
DMU & 2 & 1.07 & 0.000 & 0.000 & 0.089 & 0.000 & 5.096 & 0.023 & 0.000 \\
DMU & 4 & 1.08 & 0.000 & 0.081 & 0.000 & 3.177 & 1.652 & 0.028 & 0.000 \\
DMU & 5 & 1.05 & 0.000 & 0.066 & 0.015 & 0.000 & 2.083 & 0.000 & 0.019 \\
DMU & 13 & 1.02 & 0.071 & 0.013 & 0.000 & 2.339 & 0.000 & 0.021 & 0.009 \\
DMU & 15 & 1.14 & 0.084 & 0.000 & 0.000 & 0.000 & 0.000 & 0.042 & 0.000 \\
DMU & 19 & 1.00 & 0.085 & 0.000 & 0.000 & 1.554 & 0.000 & 0.016 & 0.014 \\
DMU & 21 & 1.02 & 0.000 & 0.084 & 0.000 & 4.489 & 1.000 & 0.025 & 0.000 \\
DMU & 22 & 1.35 & 0.000 & 0.000 & 0.091 & 9.486 & 0.000 & 0.000 & 0.000 \\
\hline
\end{tabular}

\section{Discussion and conclusion}

In this paper, we have presented an empirical investigation to measure the relative performance of 22 municipality units located in city of Tehran, Iran. The study has considered three inputs and four outputs for performance measurement and using constant return to scale data envelopment method, the study has determined the relative efficiency of all units. Based on the results of our survey, we can conclude that most units where either efficient or close to their efficient utilization of their resources. In other words, the inefficient units were only $7 \%$ off from the efficient ones and we have provided some suggestions to convert the inefficient units into efficient ones by reducing their inputs. The proposed study of this paper has also performed supper efficiency among 9 efficient units and provided appropriate ranking for these units.

\section{References}

Andersen, P., \& Petersen, N. C. (1993). A procedure for ranking efficient units in data envelopment analysis. Management Science, 39, 1261-1264.

Azar, A., Olfat, L., Khosravani, F., \& Jalali, R. (2011). A BSC method for supplier selection strategy using TOPSIS and VIKOR: A case study of part maker industry. Management Science Letters, 1(4), 559-568.

Charnes, A., Cooper, W.W., \& Rhodes, E. (1978). Measuring the efficiency of decision making units. European Journal of Operational Research, 2(6), 429-444.

Charnes, A., Cooper, W.W., Golany, B., Seiford, L.M., \& Stutz, J. (1985). Foundations of data envelopment analysis and Pareto-Koopmans empirical production functions. Journal of Econometrics, 30(1-2), 91-107.

Charnes, A., Cooper, W.W., Huang, Z.M., \& Sun, D.B. (1990). Polyhedral cone-ratio DEA models with an illustrative application to large commercial banks. Journal of Econometrics, 46(1-2), 73-91.

Cooper, W.W., Lawrence, M.S., \& Zhu, J. (2011). Handbook on data envelopment analysis. International Series in Operations Research \& Management Science, Springer, 164, 1-40.

Farkousha, S., Najafi, E \& Aryanezhad, M. (2011). A BSC-DEA approach to measure the relative efficiency of service industry: A case study of banking sector. International Journal of Industrial Engineering Computations, 2(2), 273-282.

Ghotbuee, A., Hemati, M \& Fateminezhad, R. (2012). An empirical study based on BSC-DEA to measure the relative efficiencies of different health care centers in province of Semnan, Iran. Management Science Letters, 2(7), 2643-2650.

Khaki, A., Najafi, S \& Rashidi, S. (2012). Improving efficiency of decision making units through BSCDEA technique. Management Science Letters, 2(1), 245-252.

Khani, F., Naderi, H., Zangeneh, M., \& Fazeli, E. (2012). Measuring the relative efficiency of Ilam hospitals using data envelopment analysis. Management Science Letters, 2(4), 1189-1194. 
Khouja, M. (1995). The use of data envelopment analysis for technology selection. Computers and Industrial Engineering, 28(1), 123-132.

Kuah, C.T., Wong, K.Y., \& Behrouzi, F. (2010). A review on data envelopment analysis (DEA). Proc. of $4^{\text {th }}$ Asia International Conference on Mathematical/Analytical Modelling and Computer Simulation, 168-173.

Levary, R.R. (2008). Using the analytic hierarchy process to rank foreign suppliers based on supply risks. Computers and Industrial Engineering, 55(2), 535-542.

Minciardi, R., Paolucci, M., Robba, M., \& Sacile, R. (2008). Multi-objective optimization of solid waste flows: environmentally sustainable strategies for municipalities. Waste Management, 28(11), 2202-2212.

Nourbakhsh, V., Ahmadi, A \& Mahootchi, M. (2013). Considering supply risk for supplier selection using an integrated framework of data envelopment analysis and neural networks. International Journal of Industrial Engineering Computations, 4(2), 273-284.

Rogge, N., \& De Jaeger, S. (2012). Evaluating the efficiency of municipalities in collecting and processing municipal solid waste: A shared input DEA-model. Waste Management, 32(10), 19681978.

Rogge, N., \& De Jaeger, S. (2013). Measuring and explaining the cost efficiency of municipal solid waste collection and processing services. Omega, 41(4), 653-664

Roghanian, E., \& Foroughi, A. (2010). An empirical study of Iranian regional airports using robust data envelopment analysis. International Journal of Industrial Engineering Computations, 1(1), 65-72.

lo Storto, C. (2013). Evaluating technical efficiency of Italian major municipalities: A data envelopment analysis model. Procedia - Social and Behavioral Sciences, 81, 346-350. 